\title{
Fluid management in Acute Respiratory Distress Syndrome: A narrative review
}

\author{
Jean I. Keddissi, MD, FCCP, Houssein A. Youness, MD, FCCP, Kellie R. Jones, MD, FCCP, Gary T. Kinasewitz, MD
}

\begin{abstract}
JI Keddissi, HA Youness, KR Jones, GT Kinasewitz. Fluid management in Acute Respiratory Distress Syndrome: A narrative review. Can J Respir Ther 2019;55:1-8. doi: 10.29390/cjrt-2018-016.

Acute Respiratory Distress Syndrome remains a major source of morbidity and mortality in the modern intensive care unit (ICU). Major advances in the understanding and management of this condition were made in the last two decades. The use of low tidal ventilation is a well-established therapy. Conservative fluid management is now another cornerstone of management. However, much remains to be understood in this arena. Assessing volume status in these patients may be challenging and the tools available to do so are far from perfect. Several dynamic measures including pulse pressures variation are used. Ultrasound of the lungs and the vascular system may also have a role. In addition, the type of fluid to administer when needed is still open to debate. Finally, supportive measures in these patients, early during their ICU stay and later after discharge continue to be crucial for survival and adequate recovery.
\end{abstract}

Key Words: acute lung injury; fluid replacement; mechanical ventilation

\section{INTRODUCTION}

Since its initial description in 1967 by Ashbaugh et al. [1], Acute Respiratory Distress Syndrome (ARDS) remains a serious and frequent challenge in modern intensive care units. Despite great improvement in management, mortality and morbidity continues to be significant [2], with mortality of $45 \%$ in the severe form [3]. Newer therapeutic modalities are needed, requiring better understanding of the underlying pathophysiology as well as better refinement of the tools currently at our disposal.

One of the interventions used in the management of ARDS patients is fluid therapy. This therapy poses a special dilemma as a double-edged sword. On one hand, it is frequently needed in patients with ARDS, particularly when evidence of hypoperfusion exists. On the other hand, fluid infusion and resultant volume overload leading to pulmonary edema can exacerbate the pre-existing gas exchange abnormalities.

This review includes a general overview of the management of ARDS, with a focus on fluid management. We review the underlying pathophysiology and its effect on fluid movement across the alveolarcapillary membrane, as well as the large trials that addressed the optimal fluid therapy in this syndrome.

\section{DEFINITION AND CLINICAL PICTURE}

After two decades of using the 1994 American/European Consensus Conference definition of ARDS [4], a new, revised definition was adopted [3]. Known as the Berlin definition, it requires that ARDS develop within 1 week of a known clinical insult, with bilateral radiographic opacities. The pulmonary opacities must not be related only to systolic heart failure or fluid overload. Measured at a PEEP $\geq 5 \mathrm{~cm} \mathrm{H}_{2} \mathrm{O}$, the degree of gas exchange abnormality is used to classify the syndrome as mild $\left(200<\mathrm{PaO}_{2} / \mathrm{FiO}_{2} \leq 300\right)$, moderate $\left(100<\mathrm{PaO}_{2} / \mathrm{FiO}_{2} \leq 200\right)$, or severe $\left(\mathrm{PaO}_{2} / \mathrm{FiO}_{2} \leq 100\right)$. Noninvasive ventilation is possible in the mild group. The term Acute Lung Injury (ALI), which referred to the mild form of ARDS, was removed from the new definition.

An estimate of the true incidence of ARDS varies over time, in part due to the changing definition and/or lack of application of such definition. Using the 1994 definition, a Scandinavian cohort study reported an incidence of 17.9 cases of ALI and 13.5 cases of ARDS per 100,000 (reference population $\geq 15$ years of age) [5]. A population-based cohort study in Washington estimated ARDS to occur in 64 cases/100,000 person-years, whereas ALI occurred in 86 cases/100,000 person-years [6]. The incidence of ARDS/ALI may be decreasing, owing to a decline in hospital-acquired ARDS, but confirmation of this trend is needed [7]. Better management of inciting factors such as sepsis and more judicious ventilatory strategies that avoid barotrauma and volutrauma may also be adding to this possible decrease in incidence. Finally, the syndrome is likely underreported in low-income countries, because of the lack of resources to obtain arterial blood gases and chest radiographs [8].

Sepsis is the most common cause of ARDS, with $40 \%$ of sepsis cases developing the syndrome $[9,10]$. Other etiologies include pneumonia, shock, major surgery, and trauma.

Clinically, the syndrome is characterized by the rapid onset of hypoxemic respiratory failure in the context of a predisposing underlying condition. The hypoxemia is usually severe enough to require invasive mechanical ventilation. Bilateral radiographic infiltrates are present, frequently indistinguishable from those seen in cardiogenic pulmonary edema [11]. Computed tomography most often reveals consolidation with alveolar filling, predominantly in the dependent zones [12]. In later stages, interstitial opacities with bullae formation may develop. Complications may include pulmonary hypertension, right ventricular failure [13], and the development of pneumothorax [14].

Section of Pulmonary, Critical Care and Sleep Medicine, The Oklahoma City VA HealthCare System and the University of Oklahoma Health Sciences Center, Oklahoma City, Oklahoma, USA

Correspondence: Jean I. Keddissi, MD, Section of Pulmonary, Critical Care and Sleep Medicine, University of Oklahoma Health Sciences Center, 800 Stanton L. Young Blvd., Suite 8400, Oklahoma City, OK 73104, USA. Tel.: (405) 271-6173, Fax: (405) 271-5892. Email: jean-keddissi@ouhsc.edu

Published online at https://www.cjrt.ca on 05 December 2018

This open-access article is distributed under the terms of the Creative Commons Attribution Non-Commercial License (CC BY-NC) (http:// creativecommons.org/licenses/by-nc/4.0/), which permits reuse, distribution and reproduction of the article, provided that the original work is properly cited and the reuse is restricted to noncommercial purposes. For commercial reuse, contact editor@csrt.com 


\section{Pathophysiology}

Hydrostatic and oncotic pressures across the capillary wall govern fluid movement between the capillary and the interstitial space, as described by the Starling's equation:

$$
Q_{F}=K_{F}\left[\left(P_{C}-P_{I}\right)-\sigma\left(\pi_{C}-\pi_{I}\right)\right]
$$

(Figure 1)

where $Q_{F}$ is flow across the membrane, $K_{F}$ is capillary filtration coefficient, $\mathrm{P}_{\mathrm{C}}$ is capillary hydrostatic pressure, $\mathrm{P}_{\mathrm{I}}$ is interstitial hydrostatic pressure, $\sigma$ is oncotic reflection coefficient, $\pi_{C}$ is capillary colloid osmotic pressure, and $\pi_{\mathrm{I}}$ is interstitial colloid osmotic pressure.

These pressures dictate the direction and the amount of fluid movement. In general, the net force favors ultrafiltration at the arteriolar end of the pulmonary capillaries, whereas reabsorption typically occurs at the venular end. Accumulated fluid in the interstitium is removed by the lymphatic system. In addition, tight junctions between the alveolar epithelial cells normally act as a barrier preventing alveolar flooding.

Based on the above, an increase in the capillary hydrostatic pressure or a disruption in the integrity of the alveolar-capillary membrane (with increased permeability) may result in interstitial and alveolar flooding. ARDS is an example of the latter, characterized by alveolar edema/flooding that occurs in the presence of normal capillary hydrostatic pressure. The flat type I cells (typically making up 90\% of the alveolar surface area) are injured. The cuboidal type II cells, typically more resistant to injury, would eventually differentiate into type I cells, restoring the normal alveolar architecture if the ARDS resolves [13]. The membrane injury results in massive amount of fluid and plasma proteins leaking into the alveolar space, with subsequent formation of hyaline membranes. Fluid removal from the alveolar space is also impaired.

Activated inflammatory cells, primarily macrophages and neutrophils, accumulate in the interstitium. Proinflammatory cytokines, including Interleukin (IL)-1 $\beta$, IL-8, and tumor necrosis factor (TNF)- $\alpha$, are also released into the lungs $[15,16]$ and are thought to play a role in the cellular response and microvascular injury as well as the extra pulmonary organ failures seen in ARDS [16].

Surfactant activity and composition is also affected, resulting in elevated surface tension and alveolar collapse [17], decreased lung compliance [18], impaired gas exchange, and increased pulmonary arterial pressures $[19,20]$.

Interstitial inflammation and fibrosis become the dominant pathologic findings by day 7. In a subset of patients, pulmonary fibrosis develops. It appears the presence of such fibrosis closely correlates with mortality in established ARDS [21].

\section{General management}

Recognition and treatment of the underlying etiology, such as infection, should always be a priority. In addition, adequate nutrition and prophylaxis against thromboembolic events should be considered [22].

\section{Mechanical ventilation}

The vast majority of ARDS patients require endotracheal intubation and mechanical ventilation, primarily to correct the severe hypoxemia encountered in this setting. Special attention should be paid to tidal volume to avoid ventilator-induced lung injury.

Based on a large ARDSnet study (861 patients) [23], comparing tidal volumes of 12 and $6 \mathrm{~mL} / \mathrm{kg}$ of predicted body weight (plateau pressure $\leq 50$ vs. $\leq 30 \mathrm{~cm}$ of $\mathrm{H}_{2} \mathrm{O}$ ), low tidal volume is now considered the standard of care in patients with ARDS. In this study, mortality was lower in the group treated with $6 \mathrm{~mL} / \mathrm{kg}(31.0 \%$ vs. $39.8 \%, p=0.007)$. In a porcine model of pulmonary edema, low tidal volume $(6 \mathrm{~mL} / \mathrm{kg})$ was associated with lower extravascular lung water (EVLW), as measured by the double indicator method, compared with a tidal volume of $12 \mathrm{~mL} / \mathrm{kg}$ [24].

Analyzing data from nine randomized trials, Amato et al. [25] found that the driving pressure, defined as the ratio of the tidal volume and the respiratory-system compliance, correlated best with survival in ARDS, even in patients receiving protective ventilation. This suggests that the driving pressure may be a better therapeutic target in future trials.

The use of low tidal volume may result in $\mathrm{CO}_{2}$ retention and respiratory acidosis. This permissive hypercapnia can be managed with a higher respiratory rate.

Positive End Expiratory Pressure (PEEP) is used primarily to improve oxygenation, by increasing the functional residual capacity, preventing small airways and alveoli from collapsing, thus improving the ventilation-perfusion $(\mathrm{V} / \mathrm{Q})$ matching [26-28]. The effect of PEEP on the EVLW as measured by transpulmonary thermodilution appears to be mild or negligible [29]. Side effects associated with PEEP are primarily circulatory depression and barotrauma.

Several trials were conducted to determine whether higher levels of PEEP are associated with better outcomes [30-32]. No mortality difference was seen in these trials, suggesting that the lowest PEEP associated with acceptable oxygenation and airway pressure may be used. Nevertheless, the 2016 Surviving Sepsis Campaign guidelines suggest using higher PEEP over lower PEEP in adults with sepsis-induced moderate to severe ARDS (weak recommendation, moderate quality of evidence) [33].

Finally, a recent trial showed worse outcome with a strategy that included lung recruitment and titrated PEEP according to respiratory system compliance compared with a strategy of low PEEP [34].

\section{FIGURE 1}

The normal balance of the Starling forces. Typically, a small amount of fluid is filtered into the interstitial space and is removed by the lymphatic system.

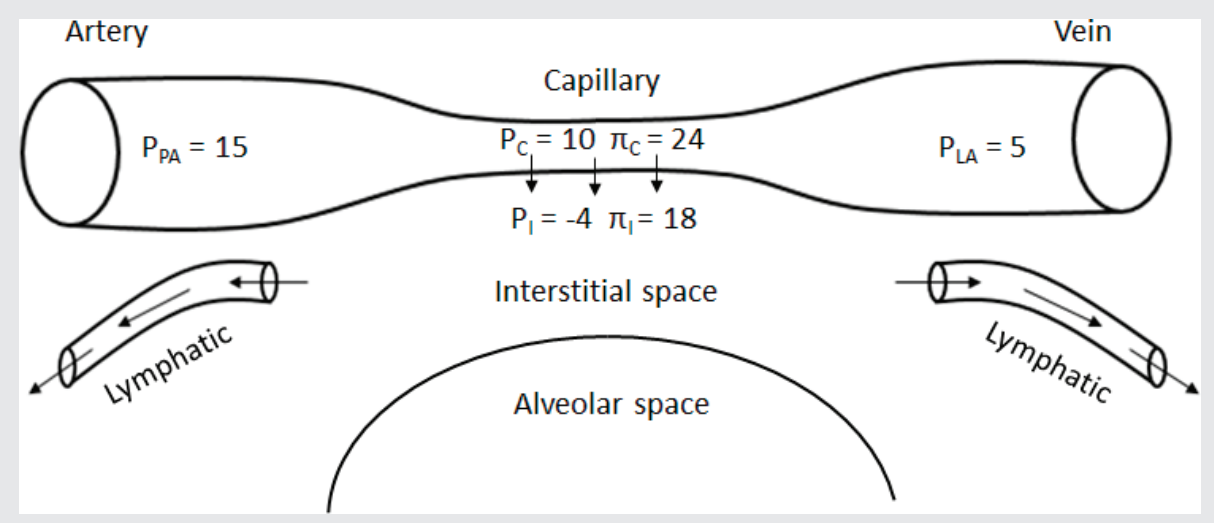




\section{Prone position}

The use of prone position in moderate to severe ARDS results in oxygenation improvement $[35,36]$. The reasons for this improvement are unclear $[16,37,38]$, but they likely include an increase in lung volume with a decrease in the amount of atelectasis and shunt fraction, better $\mathrm{V} / \mathrm{Q}$ mismatch, and release of the effect of the heart weight on the left lung. Interestingly, a small study found that the EVLW index measured by the transpulmonary thermodilution technique increased after proning $(12.7 \pm 4.7 \mathrm{vs} .14 .8 \pm 7.8 \mathrm{~mL} / \mathrm{kg})$, but the increase remained of no clinical relevance [39].

Although earlier studies did not show an effect on mortality [40, 41], a more recent trial in patients with severe ARDS $\left(\mathrm{PaO}_{2} / \mathrm{FiO}_{2}<150 \mathrm{~mm}\right.$ $\mathrm{Hg}$ ) showed a lower 28-day mortality when prone position was used for at least 16 consecutive hours [42]. Based on that, current evidence support its use in severe ARDS, including patients with sepsis-induced ARDS and $\mathrm{PaO}_{2} / \mathrm{FiO}_{2}<150 \mathrm{~mm} \mathrm{Hg}$ [33].

\section{Other supportive therapies}

Inhaled Nitric Oxide (iNO), a powerful vasodilator, improves the ventilation-perfusion mismatching, with a dose-dependent improvement in oxygenation [43]. In a small animal model of acute lung injury, iNO reduced edema formation secondary to fluid resuscitation [44]. Its use in ARDS was evaluated in multiple clinical trials [45-48]. The results are consistent with improvement in oxygenation, with no firm effect on mortality. As with any other salvage therapy, iNO may be considered in patients with refractory hypoxemia, keeping in mind the potential for side effects and the fact that any benefit is likely time limited.

Iloprost, a stable prostacyclin analogue, improves gas exchange in patients with ARDS and pulmonary hypertension [49]. However, unlike $\mathrm{iNO}$, iloprost did not attenuate lung edema in an ovine model of lung injury [50].

The use of steroids in ARDS remains one of the most controversial issues. Over the last few decades, studies have reached different conclusions when assessing the effect on mortality [51-55]. Recent guidelines from the Society of Critical Care Medicine and European Society of Intensive Care Medicine suggest their use in patients with early moderate to severe ARDS $\left(\mathrm{PaO}_{2} / \mathrm{FiO}_{2}<200 \mathrm{~mm} \mathrm{Hg}\right.$ and within 14 days of onset) (conditional recommendation, moderate quality of evidence) [56]. Any possible benefit should be weighed against the potential for adverse effects, including infections and neuromuscular weakness.

Extracorporal Membrane Oxygenation (ECMO) uses an extracorporeal circuit to directly oxygenate and remove $\mathrm{CO}_{2}$ from the blood [57]. It can be used as salvage therapy in patients with severe ARDS, but welldesigned controlled trials showing clear survival benefit are lacking. A recent international trial showed that in patients with very severe ARDS, the 60-day mortality was not significantly lower with ECMO compared with a conventional mechanical ventilation strategy that included ECMO as salvage therapy [58]. More studies are needed to define ECMO's potential role in ARDS.

High-frequency oscillatory ventilation, delivering very small tidal volumes at very high rates, was studied in ARDS. Based on a trial showing that in moderate-to-severe ARDS, its early application did not reduce, and may increase, in-hospital mortality; its use cannot be recommended in ARDS [59].

Neuromuscular blockade in ARDS results in improved oxygenation. A 2010 French trial found that the early use of Cisatracurium in severe ARDS (onset within $48 \mathrm{~h}$ ) improved the adjusted 90-day survival without increasing muscle weakness [60]. More studies are needed to confirm this finding and to determine whether this survival benefit is seen with other neuromuscular blocking agents.

Edema clearance is dependent on active $\mathrm{Na}$ transport, with water following the Na gradient [61]. In hydrostatic pulmonary edema, fluid clearance is usually maximal or submaximal in a majority of patients compared with ARDS [62]. Therefore, enhancing fluid removal from the airspace in ARDS is another attractive therapeutic modality. This process can be upregulated by catecholamine-dependent and independent mechanisms [63], including beta-2 adrenergic agonists. A single-center small randomized trial found that treating ALI/ARDS patients with intravenous salbutamol resulted in lower lung water and plateau pressure [64]. However, in another ARDS network trial, aerosolized albuterol ( $5 \mathrm{mg}$, every $4 \mathrm{~h}$ up to 10 days) was compared with saline placebo in patients with ALI [65]. No improvement in clinical outcomes was seen with albuterol in this trial. Therefore, the routine use of beta2-agonists in these patients for the sole purpose of alveolar edema clearance cannot be recommended.

\section{Fluid management and responsiveness}

Fluid management in ARDS is a complicated and delicate issue. Frequently, these patients require fluid administration, such as in cases of sepsis or septic shock. However, the underlying pathophysiology of normal pressure pulmonary edema makes it evident that fluid administration may increase the left atrial and pulmonary venous pressures, can worsen the alveolar flooding, decrease the $\mathrm{PaO} / \mathrm{FiO}_{2}$; therefore, it needs to be performed with close monitoring of the gas exchange and hemodynamic parameters. On the other hand, studies showed that induced hypotension, accompanied by a reduction in the cardiac output and the pulmonary blood flow (as seen during hemorrhagic shock), results in increased alveolar and physiological dead space [66]. This leads to worsening gas exchange, with an increase primarily in the $\mathrm{PaCO}_{2}$. In addition, therapy and/or conditions that result in the lowering of the pulmonary arterial pressure, such as vasodilator treatment for pulmonary hypertension, typically increase the intrapulmonary shunting and worsen hypoxemia [67]. This suggests that maintaining adequate volume status in these patients is paramount.

Accurate determination of the intravascular fluid status and the degree to which impaired cardiac function is contributing to the oxygenation issues are difficult to obtain clinically. Chest X-ray and blood gases are of limited value for quantifying pulmonary edema [68]. Balancing the two competing priorities (tissue perfusion and tissue oxygenation) is often challenging. Therefore, finding the optimal intravascular volumepressure with the best risk-benefit ratio is difficult.

\section{Optimal volume status}

The optimal intravascular volume maintains adequate tissue perfusion while minimizing alveolar flooding. Theoretically, if ARDS patients are kept dry, improvement in the pulmonary status including gas exchange could potentially result in improved outcomes. In fact, some retrospective studies suggested that this is indeed the case [69-72]. Alsous et al. [69] showed that in patients with septic shock, at least 1 day of negative fluid balance in the first 3 days was associated with better survival when adjusted for age, APACHE II scores, SOFA scores on days 1 and 3, and the need for mechanical ventilation. Five patients also had ARDS/ALI by day 3 [69]. In another retrospective analysis a decade earlier, Humphrey [70] found that lowering the pulmonary artery wedge pressure (PAWP) was associated with increased survival in ARDS. Using logistic regression analysis, Simmons et al. [71] found an association between weight loss and negative fluid balance and survival in ARDS. Another observational study based on prospectively collected data found that excessive fluid administration in trauma-related ARDS patients was associated with increased mortality [72]. Independent variables in this study included demographics, severity score, injury-admission delay time, first 24-h transfusion, and septic and organ failure complications. These studies were not prospectively randomized and included patients with different definition of ARDS.

A large prospective, randomized controlled trial compared conservative and liberal fluid management strategies in 1000 patients with ALI [73]. Patients were simultaneously randomized to receive either a pulmonary-artery catheter or a central venous catheter. Management was based on four variables: central venous pressure (CVP) or PAWP, depending on catheter assignment, the presence or absence of shock, oliguria, or ineffective circulation. Fluids, diuresis, or inotropic agents were used to achieve the desired variables. During the first 7 days, the mean cumulative fluid balance was $-136 \pm 491 \mathrm{~mL}$ in the conservative-strategy group and $6992 \pm 502 \mathrm{~mL}$ in the liberal-strategy group 
$(p<0.001)$. As compared with the liberal strategy, the conservative strategy had improved oxygenation index, lung injury score, and number of ventilator-free days. There was no difference in shock, use of dialysis, or in the primary outcome of 60 -day mortality $(25.5 \%$ in the conservative-strategy group vs. $28.4 \%$ in the liberal-strategy group, $p=0.30$ ). In addition, the percentage of patients receiving vasopressors did not differ significantly between the two groups. Overall, it was felt that these results support the use of a conservative fluid management strategy in patients with ALI.

Assessing volume status/fluid responsiveness CVP/PAWP

CVP and the PAWP have traditionally been used to guide fluid management in a variety of clinical scenarios, including ARDS. However, one has to remember that the relationship between these pressures and the cardiac preload is variable [74]. And even though measuring these pressures to guide therapy could theoretically result in outcome improvement, there is a very poor relationship between CVP and blood volume, and the CVP does not predict the hemodynamic response to fluid challenge [75].

Despite the central venous catheters $(\mathrm{CVC})$ limitations in this setting, Wheeler et al. [76] compared its benefits and risks to those of pulmonary-artery catheters (PAC) in ALI. PAC-guided therapy did not improve survival or organ function but was associated with more complications than CVC-guided therapy, predominantly arrhythmias. Other PAC complications included air embolism, catheter malfunction and insertion-site bleeding. This suggests that PAC should not be routinely used for the management of ALI.

Pulse pressure variation

Pulse pressure (PP) is the difference between the systolic and diastolic pressure, and it reflects the ventricular stroke volume. Pulse pressure variation (PPV) is the difference between the maximal (PPmax) and the minimal values ( $\mathrm{PPm}$ ) divided by the mean value over a single respiratory cycle (Figure 2). Appropriate measurement requires a tidal volume $\geq 8 \mathrm{~mL} / \mathrm{kg}$, the presence of sinus rhythm, and the absence of spontaneous triggering of the ventilator. This variation during positive pressure ventilation is thought to depend on the patient's position on the FrankStarling curve, with fluid-responsive patients being on the steep part of the curve. Patients who are fluid responsive are expected to have a significant PPV while mechanically ventilated (>10-12\%) [77]. However, its

\section{FIGURE 2}

Pulse Pressure Variation (PPV), maximal (PPmax), and minimal Pulse Pressure (PPm) (By ProfBondi - Own work, CC BY-SA 3.0, https://commons.wikimedia.org/w/ index. php?curid=22625470)

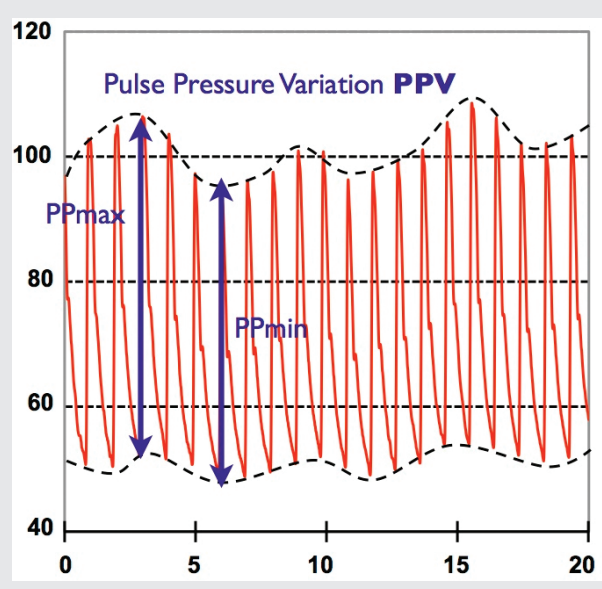

value in ARDS patients treated with protective ventilation is poor, partly owing to insufficient changes in the pleural pressure [78]. Other factors limiting its performance include the presence of arrhythmia or the presence of spontaneous respiratory efforts.

\section{Lung/central vascular ultrasound}

Lung ultrasound represents a relatively new modality to assess the EVLW, using reverberation artifacts (B lines) arising from the pleural line (Figure 3), which are believed to originate from interlobular septal thickening caused by fluid [79]. The presence of these B lines was not found to be predictive of the PAWP [80]. This is not surprising since pulmonary edema can result from cardiogenic as well as noncardiogenic etiologies. On the other hand, the presence of horizontal reverberation pattern (A lines) was found to predict a low PAWP $(\leq 18 \mathrm{mmHg})$ with a sensitivity and specificity of $50 \%$ and $93 \%$, respectively [80].

A B-line score (BLS) aimed at measuring the EVLW was found to correlate with radiological EVLW scores in patients admitted to the medical and cardiac intensive care units [81]. In patients undergoing hemodialysis (HD), the BLS measured $1 \mathrm{~h}$ after HD decreased by 2.7 B-lines for each $500 \mathrm{~mL}$ removed $(p=0.02)$ [82], indicating that lung ultrasound can be used as a repeated measure to track the resolution of pulmonary edema related to hypervolemia. In another study, patients with high altitude pulmonary edema were found to have a higher BLS score compared with control subjects $(31 \pm 11$ vs. $0.86 \pm 0.83)$, and their oxygen

\section{FIGURE 3}

Lung ultrasound showing $B$ lines (white arrows) arising from the pleural line (A), indicating the presence of septal edema, as seen in patients with ARDS and cardiogenic pulmonary edema.

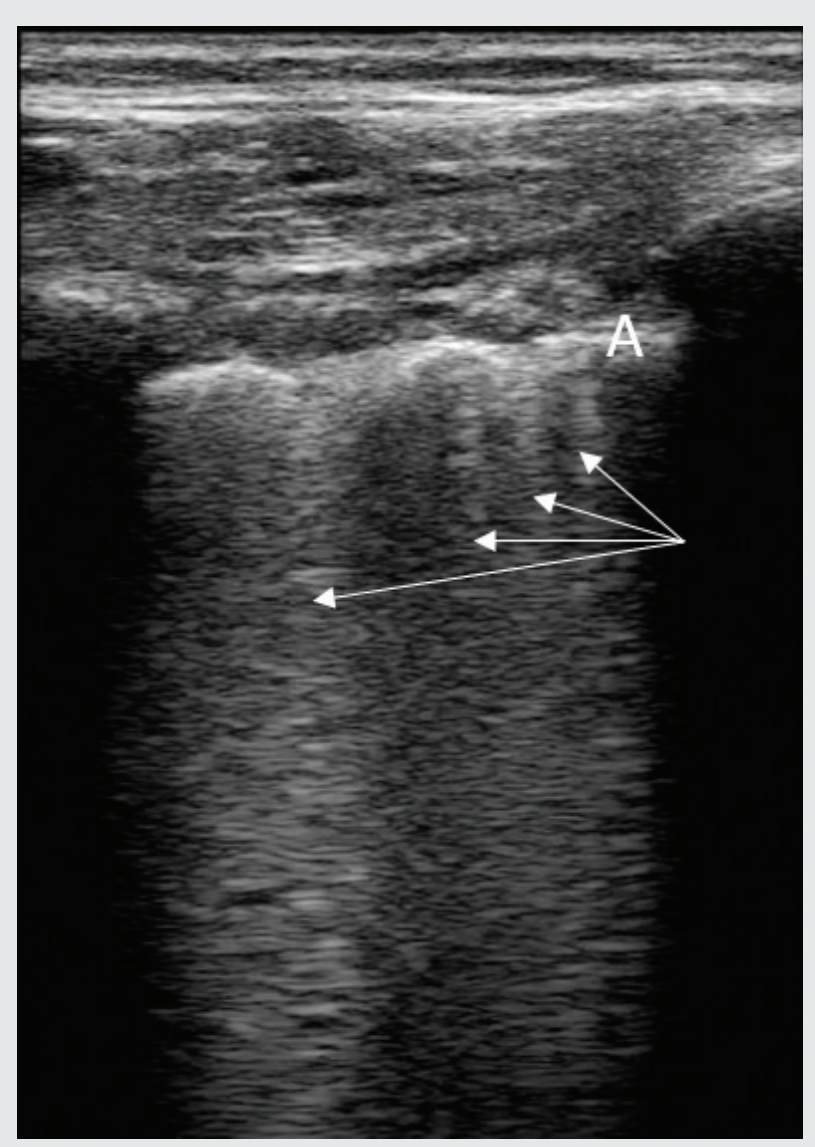


saturation decreased by $0.67 \%$ for every one point increase in the BLS ( $p<0.001$ for both comparisons) [83].

In ARDS patients, Zhao et al. [84] developed a lung ultrasound score (LUS) using a 12-region method (anterior, lateral and posterior; upper and lower; right and left chest wall), with higher scores indicating the loss of aeration or the presence pulmonary consolidation. In this study, the LUS was significantly higher on day 1 in the non-survivor group compared with the survivor group ( $20 \pm 5$ vs. $15 \pm 5, p=0.022)$. Significant correlations were also found between the LUS and EVLW indices, lung injury score, and $\mathrm{PaO} / \mathrm{FiO}_{2}\left(r^{2}=0.906,0.361,0.472, p<\right.$ 0.01 ). In another study performed in 32 patients with septic shock and ARDS, Caltabeloti et al. [85] found that aeration changes in response to early fluid loading can be detected by lung ultrasound. This suggests that lung ultrasound may have a role in recognizing and avoiding excessive fluid administration in these patients. Assessing the role vascular ultrasound may have, Allyn et al. [86] studied 45 patients with ARDS/ALI. They found that the inferior vena cava (IVC) diameter, its variation during the respiratory cycle, and the IVC distensibility did not predict tolerance to a negative fluid balance (assessed by the presence of hypotension, acute kidney injury, or need for fluid expansion).

Based on the above, lung ultrasound may be a convenient bedside tool that can be used to detect the presence of EVLW and to evaluate for septal edema following removal and/or administration of fluid. It may also have a role in predicting mortality related to ARDS. However, more studies are needed to clarify the role of this modality in guiding therapy for this population.

\section{Extravascular lung water (EVLW)}

Measuring the EVLW has been suggested to guide fluid management in patients with ARDS, and evidence suggests that maximal alveolar fluid clearance may be associated with better clinical outcomes [87]. Compared with patients with cardiac pulmonary edema, patients with ARDS have a higher EVLW with lower PAWP [88]. Normal EVLW Index is $<7 \mathrm{~mL} / \mathrm{kg}$ of predicted body weight, with $10 \mathrm{~mL} / \mathrm{kg}$ considered as the highest limit of normal. Jozwiak et al. [89] reported that EVLW and pulmonary vascular permeability indices (measured by the thermodilution curve, using the PiCCO device, Pulsion Medical Systems) are independent risk factors for the 28-day mortality in patients with ARDS. However, others found that measuring the EVLW does not distinguish patients who survive from those who do not [90]. Furthermore, EVLW did not correlate with oxygenation, indicating that even though pulmonary edema and flooding is present in these patients, it may not be the principle cause of hypoxemia. Recently, a small study by Hu [74] showed that using EVLW as a strategy for fluid management in patients with ARDS has no effect on survival but leads to lower duration of mechanical ventilation and ICU stay compared with a modality using the PAWP. However, interpreting these measurements at the bedside may not be easy, and large prospective studies assessing EVLW's role in the management of ARDS are still lacking.

\section{Fluid type}

Studies assessing the optimal fluid type to be used specifically in ARDS are lacking. In the ARDS network trial comparing conservative and liberal fluid strategies, although the protocol specified the volume of fluid to be administered, clinicians were free to select any type of fluid including: isotonic crystalloid, albumin, or blood products [73]. Hydroxyethyl starch (HES, $6 \%$ ) was compared with $0.9 \%$ saline for resuscitation in a large ICU population [91]. The study did not specify the proportion of patients with ARDS. No difference in the 90-day mortality was seen between the two groups, but more patients in the HES needed renalreplacement therapy. In a meta-analysis of critically ill patients requiring volume resuscitation, hydroxyethyl starch was associated with a significant increased risk of mortality and acute kidney injury [92]. Therefore, its use is not recommended due to serious safety concerns.

In another open-label trial, patients with severe sepsis were randomized to receive either $20 \%$ albumin and crystalloid solution or crystalloid solution alone [93]. Even though the protocol did not specify the proportion of patients with ARDS, the majority (around 80\%) required mechanical ventilation at baseline. Patients in the albumin group had a higher mean arterial pressure and a lower net fluid balance, but the 28 and 90-day mortalities were similar. In an earlier double-blind trial, $4 \%$ albumin was compared with normal saline for intravascular-fluid resuscitation in a heterogeneous group of ICU patients [94]. Similar outcomes (including mortality) were seen at 28 days. In addition, no mortality difference was seen in the pre-specified subgroup of patients with ARDS (RR 0.93, 0.61-1.41). Finally, a large meta-analysis found no evidence that colloids reduce the risk of death compared with crystalloids in patients with trauma, burns, or following surgery [95].

Based on these data, albumin does not appear to be superior to crystalloid and HES should be avoided when administering fluid to ARDS patients.

Blood transfusion aiming at increasing oxygen delivery was studied. Patients with septic shock were randomized to receive transfusion when the hemoglobin level was $7 \mathrm{~g}$ per deciliter or less or $9 \mathrm{~g}$ per deciliter or less [96]. Approximately $70 \%$ of the patients were mechanically ventilated at baseline, but no specific data were given on ARDS. Mortality at 90 days was similar between the two groups, suggesting that a conservative transfusion strategy may be appropriate in patients with ARDS, at least in those with underlying septic shock. Another study found that in critically ill patients, a restrictive transfusion strategy is at least as effective as a liberal one (possibly superior), with the potential exception of acute myocardial infarction and unstable angina [97]. Based on this, a conservative transfusion strategy appears to be the appropriate one in the ARDS population.

\section{Prognosis and outcome}

The outcome of patients with ARDS depends primarily on the underlying cause of lung injury. Survival to home discharge appears to be lowest in patients with sepsis and highest in patients with ARDS secondary to trauma [98]. Other predictors of death include age, severity of hypoxemia, and APACHE score.

Historically, the mortality ranged from $40 \%$ to $60 \%$, with the majority of deaths being related to sepsis and non-respiratory organ dysfunction [13]. More recent reports suggest that the mortality may be decreasing 23, 30, 31, 99]. Reasons for this improvement are not entirely clear, but they are likely related to the use of low tidal volume, better supportive care, and better management of sepsis.

\section{CONCLUSION}

ARDS continues to be a major challenge facing the 21st century critical care clinician. Major advances have been achieved in the last few years in understanding the pathophysiology of the syndrome, but translating this knowledge into improved outcomes has been more difficult. The use of low tidal volume, and prone position in severe cases, are the only interventions known to be unequivocally effective in reducing mortality.

Fluid management of these patients remains an area of great uncertainty. Frequent competing priorities (e.g., hypoxia and hypotension) co-exist, making this management very difficult and risky. In general, a conservative fluid strategy appears to be beneficial, without major side effects. Therefore, unless aggressive resuscitation is needed to restore a depleted intravascular volume, we recommend keeping these patients on the dry side. If fluids are to be given, one has to closely monitor the patient's hemodynamics, gas exchange, and respiratory mechanics, both for benefits and potential side effects. In experienced hands, lung ultrasound can provide evidence of worsening edema. Pressors may be used if fluids cannot be administered, particularly when gas exchange is limited. The optimal type of fluids is not well established, but it appears that the use of hydroxyethyl starch should be discouraged owing to the risk of renal failure. Crystalloids may be considered the first choice fluid for resuscitation, unless there is a specific indication for the use of colloids. Finally, since no single method is independently good enough to guide the fluid/pressor management, the clinician has to combine several clinical, laboratory, and radiographic parameters to do so.

It is very encouraging that the quality of clinical trials in ARDS has improved over the last 2 decades. However, further studies are still needed to improve our understanding of this syndrome, especially in the 
arena of fluid and hemodynamic management, to translate that into better outcome.

\section{CONTRIBUTION}

All authors have contributed to this review. All authors take responsibility for the integrity of the work as a whole, from inception to published article.

\section{DISCLOSURE}

None of the authors has a relationship to any organization with a direct financial interest in the subject of this manuscript. None of the authors has any conflict of interest to disclose.

\section{REFERENCES}

1. Ashbaugh DG, Bigelow DB, Petty TL, Levine BE. Acute respiratory distress in adults. Lancet 1967;2(7511): 319-23. doi: 10.1016/ S0140-6736(67)90168-7.

2. Erickson SE, Martin GS, Davis JL, Matthay MA, Eisner MD. Recent trends in acute lung injury mortality: 1996-2005. Crit Care Med 2009;37(5): 1574-9. doi: 10.1097/CCM.0b013e31819fefdf.

3. Force ADT, Ranieri VM, Rubenfeld GD, et al. Acute respiratory distress syndrome: The Berlin definition. JAMA 2012;307(23): 2526-33. doi: 10.1001/jama.2012.5669.

4. Bernard GR, Artigas A, Brigham KL, et al. The American-European Consensus Conference on ARDS. Definitions, mechanisms, relevant outcomes, and clinical trial coordination. Am J Respir Crit Care Med 1994;149(3 Pt 1): 818-24.

5. Luhr OR, Antonsen K, Karlsson M, et al. Incidence and mortality after acute respiratory failure and acute respiratory distress syndrome in Sweden, Denmark, and Iceland. The ARF Study Group. Am J Respir Crit Care Med 1999;159(6): 1849-61. doi: 10.1164/ajrccm.159.6.9808136.

6. Rubenfeld GD, Caldwell E, Peabody E, et al. Incidence and outcomes of acute lung injury. N Engl J Med 2005;353(16): 1685-93. doi: 10.1056/ NEJMoa050333.

7. Li G, Malinchoc M, Cartin-Ceba R, et al. Eight-year trend of acute respiratory distress syndrome: A population-based study in Olmsted County, Minnesota. Am J Respir Crit Care Med 2011;183(1): 59-66. doi: 10.1164/rccm.201003-0436OC.

8. Thompson BT, Chambers RC, Liu KD. Acute respiratory distress syndrome. N Engl J Med 2017;377(6): 562-72. doi: 10.1056/ NEJMra1608077.

9. Hudson LD, Milberg JA, Anardi D, Maunder RJ. Clinical risks for development of the acute respiratory distress syndrome. Am J Respir Crit Care Med 1995;151(2 Pt 1): 293-301. doi: 10.1164/ajrccm.151.2.7842182.

10. Pepe PE, Potkin RT, Reus DH, Hudson LD, Carrico CJ. Clinical predictors of the adult respiratory distress syndrome. Am J Surg 1982;144(1): 124-30. doi: 10.1016/0002-9610(82)90612-2.

11. Aberle DR, Wiener-Kronish JP, Webb WR, Matthay MA. Hydrostatic versus increased permeability pulmonary edema: Diagnosis based on radiographic criteria in critically ill patients. Radiology 1988;168(1): 73-9. doi: 10.1148/radiology.168.1.3380985.

12. Rouby JJ, Puybasset L, Nieszkowska A, Lu Q. Acute respiratory distress syndrome: Lessons from computed tomography of the whole lung. Crit Care Med 2003;31(4 Suppl): S285-95. doi: 10.1097/01. CCM.0000057905.74813.BC.

13. Ware LB, Matthay MA. The acute respiratory distress syndrome. N Engl J Med 2000;342(18): 1334-49. doi: 10.1056/NEJM200005043421806.

14. Weg JG, Anzueto A, Balk RA, et al. The relation of pneumothorax and other air leaks to mortality in the acute respiratory distress syndrome. N Engl J Med 1998;338(6): 341-6. doi: 10.1056/NEJM199802053380601.

15. Pugin J, Verghese G, Widmer MC, Matthay MA. The alveolar space is the site of intense inflammatory and profibrotic reactions in the early phase of acute respiratory distress syndrome. Crit Care Med 1999;27(2): 304-12. doi: 10.1097/00003246-199902000-00036.

16. Dernaika TA, Keddissi JI, Kinasewitz GT. Update on ARDS: Beyond the low tidal volume. Am J Med Sci 2009;337(5): 360-7. doi: 10.1097/ MAJ.Ob013e318195493e.

17. Spragg RG, Lewis JF, Walmrath HD, et al. Effect of recombinant surfactant protein C-based surfactant on the acute respiratory distress syndrome. N Engl J Med 2004;351(9): 884-92. doi: 10.1056/ NEJMoa033181.

18. Lewis JF, Jobe AH. Surfactant and the adult respiratory distress syndrome. Am Rev Respir Dis 1993;147(1): 218-33. doi: 10.1164/ajrccm/147.1.218.
19. Gattinoni L, Pesenti A, Avalli L, Rossi F, Bombino M. Pressure-volume curve of total respiratory system in acute respiratory failure. Computed tomographic scan study. Am Rev Respir Dis 1987;136(3): 730-6. doi: 10.1164/ajrccm/136.3.730.

20. Steltzer H, Krafft P, Fridrich P, Hiesmayr M, Hammerle AF. Right ventricular function and oxygen transport patterns in patients with acute respiratory distress syndrome. Anaesthesia 1994;49(12): 1039-45. doi: 10.1111/j.1365-2044.1994.tb04351.x.

21. Martin C, Papazian L, Payan MJ, Saux P, Gouin F. Pulmonary fibrosis correlates with outcome in adult respiratory distress syndrome. A study in mechanically ventilated patients. Chest 1995;107(1): 196-200. doi: 10.1378/chest.107.1.196.

22. Sweeney RM, McAuley DF. Acute respiratory distress syndrome. Lancet 2016;388(10058): 2416-30. doi: 10.1016/S0140-6736(16)00578-X.

23. Ventilation with lower tidal volumes as compared with traditional tidal volumes for acute lung injury and the acute respiratory distress syndrome. The Acute Respiratory Distress Syndrome Network. N Engl J Med 2000;342(18): 1301-8. doi: 10.1056/NEJM200005043421801.

24. Colmenero-Ruiz M, Fernandez-Mondejar E. Fernandez-Sacristan MA, Rivera-Fernandez R, Vazquez-Mata G. PEEP and low tidal volume ventilation reduce lung water in porcine pulmonary edema. Am J Respir Crit Care Med 1997;155(3): 964-70. doi: 10.1164/ajrccm.155.3.9117033.

25. Amato MB, Meade MO, Slutsky AS, et al. Driving pressure and survival in the acute respiratory distress syndrome. N Engl J Med 2015;372(8): 747-55. doi: 10.1056/NEJMsa1410639.

26. Falke KJ, Pontoppidan H, Kumar A, Leith DE, Geffin B, Laver MB. Ventilation with end-expiratory pressure in acute lung disease. J Clin Invest 1972;51(9): 2315-23. doi: 10.1172/JCI107042.

27. Matamis D, Lemaire F, Harf A, Teisseire B, Brun-Buisson C. Redistribution of pulmonary blood flow induced by positive end-expiratory pressure and dopamine infusion in acute respiratory failure. Am Rev Respir Dis 1984;129(1): 39-44.

28. Ralph DD, Robertson HT, Weaver LJ, Hlastala MP, Carrico CJ, Hudson LD. Distribution of ventilation and perfusion during positive end-expiratory pressure in the adult respiratory distress syndrome. Am Rev Respir Dis $1985 ; 131(1): 54-60$.

29. Jozwiak M, Teboul J-L, Monnet X. Extravascular lung water in critical care: Recent advances and clinical applications. Ann Intensive Care 2015;5(1): 38. doi: 10.1186/s13613-015-0081-9

30. Brower RG, Lanken PN, MacIntyre N, et al. Higher versus lower positive end-expiratory pressures in patients with the acute respiratory distress syndrome. N Engl J Med 2004;351(4): 327-36. doi: 10.1056/ NEJMoa032193.

31. Mercat A, Richard JC, Vielle B, et al. Positive end-expiratory pressure setting in adults with acute lung injury and acute respiratory distress syndrome: A randomized controlled trial. JAMA 2008;299(6): 646-55. doi: 10.1001/jama.299.6.646.

32. Meade MO, Cook DJ, Guyatt GH, et al. Ventilation strategy using low tidal volumes, recruitment maneuvers, and high positive end-expiratory pressure for acute lung injury and acute respiratory distress syndrome: A randomized controlled trial. JAMA 2008;299(6): 637-45. doi: 10.1001/ jama.299.6.637.

33. Rhodes A, Evans LE, Alhazzani W, et al. Surviving sepsis campaign: International guidelines for management of sepsis and septic shock: 2016. Intensive Care Med 2017;43(3): 304-77. doi: 10.1007/ s00134-017-4683-6.

34. Writing Group for the Alveolar Recruitment for Acute Respiratory Distress Syndrome Trial ICavalcanti AB, Suzumura EA, et al. Effect of lung recruitment and titrated Positive End-Expiratory Pressure (PEEP) vs Low PEEP on mortality in patients with acute respiratory distress syndrome: A randomized clinical trial. JAMA 2017;318(14): 1335-45. doi: 10.1001/jama.2017.14171.

35. Pelosi P, Tubiolo D, Mascheroni D, et al. Effects of the prone position on respiratory mechanics and gas exchange during acute lung injury. Am J Respir Crit Care Med 1998;157(2): 387-93. doi: 10.1164/ ajrccm.157.2.97-04023.

36. Albert RK, Leasa D, Sanderson M, Robertson HT, Hlastala MP. The prone position improves arterial oxygenation and reduces shunt in oleic-acid-induced acute lung injury. Am Rev Respir Dis 1987;135(3): 628-33

37. Lamm WJ, Graham MM, Albert RK. Mechanism by which the prone position improves oxygenation in acute lung injury. Am J Respir Crit Care Med 1994;150(1): 184-93. doi: 10.1164/ajrccm.150.1.8025748.

38. Pelosi P, Brazzi L, Gattinoni L. Prone position in acute respiratory distress syndrome. Eur Respir J 2002;20(4): 1017-28. doi: 10.1183/09031936.02.00401702. 
39. Brucken U, Grensemann J, Wappler F, Sakka SG. Influence of prone positioning on the measurement of transpulmonary thermodilution-derived variables in critically ill patients. Acta Anaesthesiol Scand 2011;55(9): 1061-7. doi: 10.1111/j.1399-6576.2011.02519.x.

40. Gattinoni L, Tognoni G, Pesenti A, et al. Effect of prone positioning on the survival of patients with acute respiratory failure. N Engl J Med 2001;345(8): 568-73. doi: 10.1056/NEJMoa010043.

41. Guerin C, Gaillard S, Lemasson S, et al. Effects of systematic prone positioning in hypoxemic acute respiratory failure: A randomized controlled trial. JAMA 2004;292(19): 2379-87. doi: 10.1001/jama.292.19.2379.

42. Guerin C, Reignier J, Richard JC, et al. Prone positioning in severe acute respiratory distress syndrome. N Engl J Med 2013;368(23): 2159-68. doi: 10.1056/NEJMoa1214103.

43. Gerlach H, Rossaint R, Pappert D, Falke KJ. Time-course and doseresponse of nitric oxide inhalation for systemic oxygenation and pulmonary hypertension in patients with adult respiratory distress syndrome. Eur J Clin Invest 1993;23(8): 499-502. doi: 10.1111/j.1365-2362.1993. tb00797.x.

44. Stubbe HD, Westphal M, Van Aken H, et al. Inhaled nitric oxide reduces lung edema during fluid resuscitation in ovine acute lung injury. Intensive Care Med 2003;29(10): 1790-7. doi: 10.1007/s00134-003-1790-3.

45. Taylor RW, Zimmerman JL, Dellinger RP, et al. Low-dose inhaled nitric oxide in patients with acute lung injury: A randomized controlled trial. JAMA 2004;291(13): 1603-9. doi: 10.1001/jama.291.13.1603.

46. Dellinger RP, Zimmerman JL, Taylor RW, et al. Effects of inhaled nitric oxide in patients with acute respiratory distress syndrome: Results of a randomized phase II trial. Inhaled Nitric Oxide in ARDS Study Group. Crit Care Med 1998;26(1): 15-23. doi: 10.1097/00003246-199801000-00011.

47. Borelli M, Lampati L, Vascotto E, Fumagalli R, Pesenti A. Hemodynamic and gas exchange response to inhaled nitric oxide and prone positioning in acute respiratory distress syndrome patients. Crit Care Med 2000;28(8): 2707-12. doi: 10.1097/00003246-200008000-00004.

48. Papazian L, Bregeon F, Gaillat F, et al. Respective and combined effects of prone position and inhaled nitric oxide in patients with acute respiratory distress syndrome. Am J Respir Crit Care Med 1998;157(2): 580-5. doi: 10.1164/ajrccm.157.2.9705046.

49. Sawheny E, Ellis AL, Kinasewitz GT. Iloprost improves gas exchange in patients with pulmonary hypertension and ARDS. Chest 2013;144(1): 55-62. doi: 10.1378/chest.12-2296.

50. Hucklenbruch C, Hinder F, Berger C, et al. Effects of inhaled aerosolized iloprost and inhaled $\mathrm{NO}$ on pulmonary circulation and edema formation in ovine lung injury. Shock (Augusta, Ga 2008;30(1): 75-80. doi: 10.1097/SHK.0b013e31815dd1ad.

51. Bernard GR, Luce JM, Sprung CL, et al. High-dose corticosteroids in patients with the adult respiratory distress syndrome. N Engl J Med 1987;317(25): 1565-70. doi: 10.1056/NEJM198712173172504.

52. Luce JM, Montgomery AB, Marks JD, Turner J, Metz CA, Murray JF. Ineffectiveness of high-dose methylprednisolone in preventing parenchymal lung injury and improving mortality in patients with septic shock. Am Rev Respir Dis 1988;138(1): 62-8. doi: 10.1164/ajrccm/138.1.62.

53. Meduri GU, Golden E, Freire AX, et al. Methylprednisolone infusion in early severe ARDS: Results of a randomized controlled trial. Chest 2007;131(4): 954-63. doi: 10.1378/chest.06-2100.

54. Meduri GU, Headley AS, Golden E, et al. Effect of prolonged methylprednisolone therapy in unresolving acute respiratory distress syndrome: A randomized controlled trial. JAMA 1998;280(2): 159-65. doi: 10.1001/jama.280.2.159.

55. Steinberg KP, Hudson LD, Goodman RB, et al. Efficacy and safety of corticosteroids for persistent acute respiratory distress syndrome. $\mathrm{N} \mathrm{Engl}$ J Med 2006;354(16): 1671-84. doi: 10.1056/NEJMoa051693.

56. Annane D, Pastores SM, Rochwerg B, et al. Guidelines for the Diagnosis and Management of Critical Illness-Related Corticosteroid Insufficiency (CIRCI) in Critically Ill Patients (Part I): Society of Critical Care Medicine (SCCM) and European Society of Intensive Care Medicine (ESICM) 2017. Crit Care Med 2017;45(12): 2078-88. doi: 10.1097/ ccm.0000000000002737.

57. Brodie D, Bacchetta M. Extracorporeal membrane oxygenation for ARDS in adults. N Engl J Med 2011;365(20): 1905-14. doi: 10.1056/ NEJMct1103720.

58. Combes A, Hajage D, Capellier G, et al. Extracorporeal Membrane Oxygenation for Severe Acute Respiratory Distress Syndrome. N Engl J Med 2018;378(21): 1965-75. doi: 10.1056/NEJMoa1800385.

59. Ferguson ND, Cook DJ, Guyatt GH, et al. High-frequency oscillation in early acute respiratory distress syndrome. N Engl J Med 2013;368(9): 795-805. doi: 10.1056/NEJMoa1215554.
60. Papazian L, Forel J-M, Gacouin A, et al. Neuromuscular Blockers in Early Acute Respiratory Distress Syndrome. N Engl J Med 2010;363(12): 1107-16. doi: 10.1056/NEJMoa1005372.

61. Mutlu GM, Sznajder JI. Mechanisms of pulmonary edema clearance. Am J Physiol 2005;289(5): L685-95. doi: 10.1152/ajplung.00247.2005.

62. Neamu RF, Martin GS, Fluid management in acute respiratory distress syndrome. Curr Opin Crit Care 2013;19(1): 24-30. doi: 10.1097/ MCC.0b013e32835c285b.

63. Guidot DM, Folkesson HG, Jain L, Sznajder JI, Pittet JF, Matthay MA. Integrating acute lung injury and regulation of alveolar fluid clearance. Am J Physiol 2006;291(3): L301-6. doi: 10.1152/ajplung. 00153.2006

64. Perkins GD, McAuley DF, Thickett DR, Gao F. The beta-agonist lung injury trial (BALTI): A randomized placebo-controlled clinical trial. Am J Respir Crit Care Med 2006;173(3): 281-7. doi: 10.1164/ rccm.200508-1302OC.

65. National Heart L, Blood Institute Acute Respiratory Distress Syndrome Clinical Trials NMatthay MA, et al. Randomized, placebo-controlled clinical trial of an aerosolized beta(2)-agonist for treatment of acute lung injury. Am J Respir Crit Care Med 2011;184(5): 561-8. doi: 10.1164/ rccm.201012-2090OC

66. Leigh JM, Pulmonary circulation and ventilation. Postgrad Med J 1974;50(587): 562-5. doi: 10.1136/pgmj.50.587.562.

67. Kleinsasser A, Loeckinger A, Hoermann C, et al. Sildenafil Modulates Hemodynamics and Pulmonary Gas Exchange. Am J Respir Crit Care Med 2001;163(2): 339-43. doi: 10.1164/ajrccm.163.2.2003021.

68. Sakka SG, Extravascular lung water in ARDS patients. Minerva Anestesiol 2013;79(3): 274-84

69. Alsous F, Khamiees M, DeGirolamo A, Amoateng-Adjepong Y, Manthous CA, Negative fluid balance predicts survival in patients with septic shock: A retrospective pilot study. Chest 2000;117(6): 1749-54. doi: 10.1378/chest.117.6.1749.

70. Humphrey H, Hall J, Sznajder I, Silverstein M, Wood L. Improved survival in ARDS patients associated with a reduction in pulmonary capillary wedge pressure. Chest 1990;97(5): 1176-80. doi: 10.1378/ chest.97.5.1176.

71. Simmons RS, Berdine GG, Seidenfeld JJ, et al. Fluid balance and the adult respiratory distress syndrome. Am Rev Respir Dis 1987;135(4): 924-9. doi: 10.1164/arrd.1987.135.4.924.

72. Navarrete-Navarro P, Rodriguez A, Reynolds N, et al. Acute respiratory distress syndrome among trauma patients: Trends in ICU mortality, risk factors, complications and resource utilization. Intensive Care Med 2001;27(7): 1133-40. doi: 10.1007/s001340100955.

73. Wiedemann HP, Wheeler AP, Bernard GR, et al. Comparison of two fluid-management strategies in acute lung injury. N Engl J Med 2006;354(24): 2564-75. doi: 10.1056/NEJMoa062200.

74. Hu W, Lin CW, Liu BW, Hu WH, Zhu Y, Extravascular lung water and pulmonary arterial wedge pressure for fluid management in patients with acute respiratory distress syndrome. Multidiscip Respir Med 2014;9(1): 3 . doi: 10.1186/2049-6958-9-3

75. Marik PE, Baram M, Vahid B. Does central venous pressure predict fluid responsiveness?*. A systematic review of the literature and the tale of seven mares. Chest 2008;134(1): 172-8. doi: 10.1378/chest.07-2331.

76. Wheeler AP, Bernard GR, Thompson BT, Schoenfeld D, Wiedemann $\mathrm{HP}$, deBoisblanc B, et al. Pulmonary-artery versus central venous catheter to guide treatment of acute lung injury. N Engl J Med 2006;354(21): 2213-24. doi: 10.1056/NEJMoa061895.

77. Teboul JL, Monnet X, Pulse pressure variation and ARDS. Minerva Anestesiol 2013;79(4): 398-407

78. Lakhal K, Ehrmann S, Benzekri-Lefevre D, et al. Respiratory pulse pressure variation fails to predict fluid responsiveness in acute respiratory distress syndrome. Crit Care (London, England 2011;15(2): R85. doi: $10.1186 / \mathrm{cc} 10083$.

79. Lichtenstein D, Mézière G, Biderman P, Gepner A, Barré O. The Comettail Artifact. Am J Respir Crit Care Med 1997;156(5): 1640-6. doi: 10.1164/ajrccm.156.5.96-07096.

80. Lichtenstein DA, Mezière GA, Lagoueyte J-F, Biderman P, Goldstein I, Gepner A. A-lines and b-lines: Lung ultrasound as a bedside tool for predicting pulmonary artery occlusion pressure in the critically ill. Chest 2009;136(4): 1014-20. doi: 10.1378/chest.09-0001.

81. Jambrik Z, Monti S, Coppola V, et al. Usefulness of ultrasound lung comets as a nonradiologic sign of extravascular lung water. Am J Cardiol 2004;93(10): 1265-70. doi: 10.1016/j.amjcard.2004.02.012.

82. Noble VE, Murray AF, Capp R, Sylvia-Reardon MH, Steele DJ, Liteplo A. Ultrasound assessment for extravascular lung water in patients 
undergoing hemodialysis: Time course for resolution. Chest 2009;135(6): 1433-9. doi: 10.1378/chest.08-1811.

83. Fagenholz PJ, Gutman JA, Murray AF, Noble VE, Thomas SH, Harris NS. Chest ultrasonography for the diagnosis and monitoring of high-altitude pulmonary edema. Chest 2007;131(4): 1013-8. doi: 10.1378/ chest.06-1864.

84. Zhao Z, Jiang L, Xi X, et al. Prognostic value of extravascular lung water assessed with lung ultrasound score by chest sonography in patients with acute respiratory distress syndrome. BMC Pulm Med 2015;15(1): 98. doi: 10.1186/s12890-015-0091-2

85. Caltabeloti FP, Monsel A, Arbelot C, et al. Early fluid loading in acute respiratory distress syndrome with septic shock deteriorates lung aeration without impairing arterial oxygenation: A lung ultrasound observational study. Crit Care 2014;18(3): R91. doi: 10.1186/cc13859

86. Allyn J, Allou N, Dib M, et al. Echocardiography to predict tolerance to negative fluid balance in acute respiratory distress syndrome/ acute lung injury. J Crit Care 2013;28(6): 1006-10. doi: 10.1016/j. jcrc.2013.07.044.

87. Ware LB, Matthay MA. Alveolar fluid clearance is impaired in the majority of patients with acute lung injury and the acute respiratory distress syndrome. Am J Respir Crit Care Med 2001;163(6): 1376-83. doi: 10.1164/ajrccm.163.6.2004035.

88. Sibbald WJ, Short AK, Warshawski FJ, Cunningham DG, Cheung H. Thermal dye measurements of extravascular lung water in critically ill patients. Intravascular Starling forces and extravascular lung water in the adult respiratory distress syndrome. Chest 1985;87(5): 585-92. doi: 10.1378/chest.87.5.585.

89. Jozwiak M, Silva S, Persichini R, et al. Extravascular lung water is an independent prognostic factor in patients with acute respiratory distress syndrome. Crit Care Med 2013;41(2): 472-80. doi: 10.1097/ CCM.0b013e31826ab377.

90. Brigham KL, Kariman K, Harris TR, Snapper JR, Bernard GR, Young SL. Correlation of oxygenation with vascular permeability-surface area but not with lung water in humans with acute respiratory failure and pulmonary edema. J Clin Invest 1983;72(1): 339-49. doi: 10.1172/ JCI110974.

91. Myburgh JA, Finfer S, Bellomo R, et al. Hydroxyethyl Starch or Saline for Fluid Resuscitation in Intensive Care. N Engl J Med 2012;367(20): 1901-11. doi: 10.1056/NEJMoa1209759.

92. Zarychanski R, Abou-Setta AM, Turgeon AF, et al. Association of hydroxyethyl starch administration with mortality and acute kidney injury in critically ill patients requiring volume resuscitation: A systematic review and meta-analysis. JAMA 2013;309(7): 678-88. doi: 10.1001/ jama.2013.430.

93. Caironi P, Tognoni G, Masson S, et al. Albumin Replacement in Patients with Severe Sepsis or Septic Shock. N Engl J Med 2014;370(15): 1412-21. doi: 10.1056/NEJMoa1305727.

94. Finfer S, Bellomo R, Boyce N, et al. A comparison of albumin and saline for fluid resuscitation in the intensive care unit. N Engl J Med 2004;350(22): 2247-56. doi: 10.1056/NEJMoa040232.

95. Perel P, Roberts I, Ker K. Colloids versus crystalloids for fluid resuscitation in critically ill patients. Cochrane Database Syst Rev 2013(2): CD000567. doi: 10.1002/14651858.CD000567.pub6

96. Holst LB, Haase N, Wetterslev J, et al. Lower versus Higher Hemoglobin Threshold for Transfusion in Septic Shock. N Engl J Med 2014;371(15): 1381-91. doi: 10.1056/NEJMoa1406617.

97. Hébert PC, Wells G, Blajchman MA, et al. A Multicenter, Randomized, Controlled Clinical Trial of Transfusion Requirements in Critical Care. N Engl J Med 1999;340(6): 409-17. doi: 10.1056/nejm199902113400601.

98. Eisner MD, Thompson T, Hudson LD, et al. Efficacy of low tidal volume ventilation in patients with different clinical risk factors for acute lung injury and the acute respiratory distress syndrome. Am J Respir Crit Care Med 2001;164(2): 231-6. doi: 10.1164/ajrccm.164.2.2011093.

99. Esteban A, Frutos-Vivar F, Muriel A, et al. Evolution of mortality over time in patients receiving mechanical ventilation. Am J Respir Crit Care Med 2013;188(2): 220-30. doi: 10.1164/rccm.201212-2169OC. 